\title{
Rethinking The Use Of Causal Theories In Social Sciences: A Focus On Accounting And Finance
}

Charmaine Scrimnger-Christian, North-West University (VTC), South Africa Saratiel Wedzerai Musvoto, North-West University (VTC), South Africa

\begin{abstract}
This study highlights the problems associated with the use of deterministic models in social scientific disciplines such as accounting and finance. A deterministic theory connotes a selfdefining set of physical relations and it yields a set of mathematical functions, parameterized by time, which describes how a set of ideal measure numbers changes with the time parameter while statistical models are used to describe the distribution of variations of concrete measured data from the ideal mathematical law. In this study, it is argued that in disciplines such as accounting and finance there are no appropriately defined ideal mathematical laws. Moreover, it is suggested that phenomena in accounting and finance do not exhibit characteristics that facilitate an appropriate description of deterministic models. If this is the case, it follows that there are no concretely measurable data in these disciplines and consequently these data have variations whose distributions from undefined ideal mathematical laws cannot be described. Hence, it is suggested in this study that linear models can only yield misleading information in accounting and finance unless they are based on concretely measurable relations.
\end{abstract}

Keywords: Linear Models; Ideal Norm; Causal or Deterministic Theories; Regression Analysis

\section{INTRODUCTION}

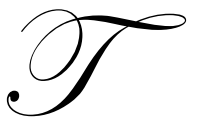

he use of linear statistical models in accounting and finance originates from describing point estimates in these disciplines as point measurements. Numerical assignments in accounting and finance are regarded to be measurements (Haugens, 2001; IASB, 2009). According to Luce, Krantz, Suppes and Tyersk (1971) all measurements are supposed to be empirically testable. This implies that all measurements arise from scientific knowing, i.e. they arise from a process governed by a deterministic or causal theory. A causal theory is represented by the construction of an ideal relational norm for sensible data from which individual cases do not systematically diverge (Heelan, 1965). This means that the production of point measurements should not be done through a random process, i.e. the process should be standardized. Furthermore, it is clear that the construction of an ideal norm establishes the standard against which measurements can be compared. As a result, points measurements produced in this way can be used to predict the state of an isolated system at any future epoch. In linear statistical models, such as in regression analysis, the goal of a regression study is to build an equation that allows the description, prediction and control of a dependent variable on the basis of one or more independent variables (Bowerman \& O'Connell, 1990). In this case, it is assumed that given the initial conditions at any arbitrary point in time it should be possible to estimate the value of the dependent variable. This viewpoint only works if the variables in the model are appropriately defined.

However, recent studies in accounting and finance (Musvoto, 2008, 2011a, 2011b; Staubus, 2004; Walker \& Jones, 2003) have shown that accounting and finance variables are defined in a way that is vague and ambiguous. Yet, according to literature on causal theories (Heelan,1965), all variables in a deterministic model should have precise definitions. This suggests that causal theories are inappropriately applied to accounting and finance situations. Given the above, this study discusses the appropriateness of using causal or deterministic theories in 
preparing financial information. This study commences with a literature review in Section 2, which is followed by a discussion on the implications of the ambiguity and vagueness of accounting and finance definitions in the use of causal theories in the disciplines in Section 3. In Section 4, the role of fundamental measurement in formulating causal theories and its implications to accounting and finance is discussed. Section 5 concludes the study.

\section{LITERATURE REVIEW}

The disciplines of accounting and finance are classified as social sciences. This means that the determination of point estimates in these disciplines is bound by principles that establish point measurements in social sciences. According to Luce et al. (1971), physical measures under the auspices of the representational theory of measurement are commonly employed in determining point measurements in social sciences, e.g. in a discipline such as psychology much progress has been made in the use of physical measures. They point out that a full measurement analysis of the structure of the social scientific phenomenon is called for before the establishment of the physical measure. This means that numerical assignments in accounting and finance should not be based on correlates related to psychological dimensions by unknown laws. Rather an exact and precise relationship should be known before an assignment can be considered to be a transformation that is based on an appropriately defined homomorphism. Narens (2002) also point out that a qualitative description of the situation, which is to be mapped, should be given through a relational structure. A relational structure, in this case, specifies all the properties of the situation that are important in its mapping. Such a specification allows the properties of the situation to be given an empirical identification.

However, in social sciences there are also situations in which physical measurements are used in a way that does not engage the full measurement structures that underlie them. According to Luce et al. (1971), such cases occur in situations where the physical measure is thought to be an order preserving index of some hypothetical underlying quantity, which itself has not received a full measurement analysis. These cases do not involve concrete knowledge of the underlying structure, i.e. the underlying structure has no known empirically testable properties. In actual fact, it is not known whether the true properties of the underlying structure can be represented by the abstract structure of choice. In this instance, a fundamentally measured quantity does not emerge, but rather an imperfect index of the underlying structure that might not even prove to be monotonic emerges. As a result, numerous indices can be assigned to represent the same underlying structure, which themselves are not monotonically related. Moreover, it is important to note that a fundamentally measured quantity only emerges if there is an explicit theory into which the underlying structure is incorporated.

In accounting and finance linear statistical models are applied under the premise that the variables used in the analysis are products of fundamental measurement processes. Most linear statistical models used in accounting and finance are based on the concept of regression analysis. According to Bowerman and O'Connell (1990), regression analysis is a statistical methodology that is used to relate variables. They point out that it is used in instances where one wishes to relate a variable of interest, which is called the dependent variable or response variable, to one or more predictor or independent variables. In this case, it is clear that such models are only used if there is a clear definition of the variables whose relationship is sought. Therefore, there must be a deterministic or causal theory that underlies the definition of each variable. However, in finance, linear models are used in determining the variability in the return on a stock when there are changes in the market returns. For example, in determining the relationship between the returns on a stock and the market returns, Haugens (2001) points out that it is important to draw the line of best fit known as the stock's characteristic line. He highlights that the characteristic line shows the return you expect the stock to produce given that a particular rate of return appears for the market. In measurement terms, it may be argued that the slope of the characteristic line is the scale of measurement that maps market return onto the stock's return. However, Musvoto (2008) highlights that the concept of return is constructed from a vaguely defined accounting concept of value. For this reason the concept of return is also vague. Hence, it is not possible to define the relationship between the market return and the stock's return using a linear model. The return of a stock is an appropriately defined variable that requires full measurement analysis. It follows therefore, that the concept of return on which most of the finance principles and concepts are based is not constructed out of scientific knowing. 
Moreover, in the accounting discipline authors such as Vickrey (1970) highlight that the accounting concept of measurement is based on the measurement of a vaguely defined attribute of the elements of the financial statements. He drew the conclusion that accounting is not a measurement discipline and that there is no property that is measurable in accounting apart from the numerosity of monetary units. In addition, authors such as Abdel-Magid (1979), Chambers (1997), Musvoto (2008) and Staubus (1985) also highlight the lack of success of the accounting discipline in developing a theory of accounting measurement. This highlights that numerical assignments in accounting are pre-theoretic. All measurement magnitudes must be theoretically determined reflections of objectively existing entities (Decoene, Onghena \& Jannsen, 1995). Thus, it can be argued that there is sufficient evidence to suggest that numerical assignments in the accounting process of depreciation could be anything other than measurement magnitudes. In this case, in an idealized relational norm, all accounting variables must be described operationally through appropriate measuring processes, which map them onto the real line. If this is the case, it follows that the absence of appropriately defined accounting variables implies that it is not possible to construct an ideal relational norm for accounting data from which they are not expected to systematically diverge.

\section{THE AMBIGUITY AND VAGUENESS OF ACCOUNTING AND FINANCE DEFINITIONS}

In Section 2 it has been argued that the application of linear models in accounting and finance requires the precise specification of the variables to be used in the equation to be given. According to Heelan (1965), the equations described under deterministic or causal theories are such that given the initial values of all the variables the state of an isolated system at any future (or past) epoch can be calculated exactly. He argues that this kind of theory is called a deterministic or causal theory since it allows the calculation of the future or past state of an isolated system if its state is given at an arbitrary origin of time. This viewpoint implies that if accounting systems are represented using deterministic models, then their state at any point in time can be predicted if their initial values are given at an arbitrary point in time. However, the question is how well the deterministic or causal theories work in accounting. The answer to this question lies, as outlined in the paragraphs above, in determining whether accounting variables facilitate the use of deterministic models in any way. If, as outlined above, deterministic models require the precise specification of the variables to be used in the equation, then accounting variables must be defined in a way that reflects dichotomy, i.e. the definitions must abide by the law of the excluded middle.

However, the phenomenon of vagueness and ambiguity has been observed in accounting. Therefore, in the accounting discipline, it has been observed that in some instances deterministic or causal theories do not work. According to Black (1963), ambiguity and vagueness exists when a word or concept has multiple meanings and is used to describe distinguishable sub-concepts or when the word or concept has no precise shape or boundaries. This means that the information about variables that is used in deterministic models should not reflect any signs of vagueness or ambiguity. Authors such as Ellsberg (1961,1963) and Fellner (1961) have noted that ambiguity and vagueness exist in many accounting and auditing decisions. They also argue that accountants have not incorporated ambiguity and vagueness into decision analysis, either treating them as if they did not exist or treating them as if they were random. It can be argued that this neglect of vagueness in the accounting environment has compromized the empirical validity of accounting information. Consequently, the reliability of accounting information is also compromized and for this reason usefulness of accounting information is limited and its applicability restricted One can therefore argue that the existence of vagueness and ambiguity in accounting implies that deterministic or causal theories have limited applicability in accounting.

The International Accounting Standards (2009) display signs of vagueness and ambiguity in defining the attributes of the elements of the financial statements, whose measurement is necessary in the preparation of accounting information. For example, the IASB (2010, Para 83:A30) framework for financial reporting points out that the elements of financial statements can only be recognized in financial statements if they have a cost or value that can be measured reliably. However, there is no mention of the properties that cost or value must have in order to be measurable. According to Stevens (1951), the properties of the objects to be measured must be specified so that measurements of it can be contrived to meet the operational definition of measurement. In this case it is necessary to specify the properties of cost or value, so that measurements of cost or value taken under non-standards conditions can be compared. In accounting literature (IASB, 2010) the equation, Assets = Owner's Equity + Liabilities, is a deterministic or causal model used to describe the relationship of the different components of the statement of financial position. With this equation it is possible to determine the financial position of an entity at any arbitrary 
point in time given the initial conditions if the variables are defined in a way consistent with the principles of deterministic or causal theories, i.e. as Heelan (1965) points out the variables in the equation must be described operationally through appropriate measuring processes that map them onto the number field. This means that every variable in the equation must be supported by an underlying theory of measurement. However, studies in accounting measurement (Chambers, 1997; Musvoto \& Gouws, 2010; Staubus, 2004) indicate that there is no theory of measurement that supports the numerical assignments in accounting. For this reason, it can be argued that the values of the variables in the accounting equation cannot be determined through appropriate measurement processes.

Moreover, in the accounting discipline allocation methods are used, for example, in calculating depreciation. It is important to note that all allocation methods are arbitrary (Sterling, 1979). This means that they do not refer to real world phenomena. It is therefore not possible to test the truth or falsity of each of the allocation methods. There are no set standards against which allocations can be made and there are no nominated scalars of the allocation process. In the finance discipline, Musvoto (2011a) notes that models that form the foundations of finance theory, such as the portfolio theory of Markowitz (1952), the capital asset pricing model (CAPM) developed by, Mossin (1966) and Sharpe (1964), are based on the concept of return on investment. He argues that the return on an investment is arrived at after allowing for expenses on the income of the investment and this process uses conventional accounting rules. As a result, this also carries over accounting judgments into these models. Therefore, the vagueness and ambiguity of accounting judgments are also incorporated into finance models.

In addition, it is important to note that deterministic or causal theories serve two purposes (Heelan, 1965), i.e. they connotes a self-defining set of physical relations and yield a number of mathematical functions, parameterized by time, which describe how a set of ideal measure numbers changes with the time parameter. Therefore, a deterministic or causal theory in accounting or finance does not describe an individual entity in accounting or finance, but compares the theory with the constructed model of individual instances in accounting or finance. Hence, if the causal theory is poorly constructed no meaningful comparison can be made.

\section{FUNDAMENTAL MEASUREMENT AND DETERMINISTIC OR CAUSAL THEORIES IN ACCOUNTING AND FINANCE}

Deterministic or causal theories are based on the concept of fundamental measurement. The concept of fundamental measurement is common in natural sciences especially in physical ones. According to Mattessich (1964), fundamental measurement is a form of measurement in which measurement values are inferred through natural laws. He argues that in this form of measurement a physical structure is discovered and its properties are represented by a numerical structure in a way that preserves the properties of the physical structure. This viewpoint is consistent with the principles of the deterministic or causal theories, i.e. the deterministic model should connote a self-defining set of physical relations. Accounting and finance are classified as social sciences (Flanders, 1961; Ryan, Scapens \& Theobald, 2002) and thus fundamental measurement does not fit the attribute of social scientific phenomena exactly. According to Luce, Krantz, Suppes and Tversk (1990), physical measurements are sometimes used in social and behavioral sciences in a way that does not engage the full measurement structures that underlie them. They argue that this is because phenomena in social and behavioral sciences cannot be readily inferred through natural laws, as they are mostly dependent on the intuition of the experimenter. If this is the case, deterministic or causal theories are not readily applicable to accounting and finance. In accounting the use of causal theories in a way that does not fully complement fundamental measurement is notable. For example, according to Willet (1992), depreciation possesses measurement dimensions that are synonymous with fundamental measurement. He defines depreciation as a time average with measurement dimensions of cost per unit of time. This makes depreciation the value of a measurement function that maps a particular empirical relational structure onto an abstract structure with units of cost per unit of time. Willet (1992) used straight-line depreciation to illustrate that depreciation is a measure that is produced by relating three fundamental laws (i.e. cost, length of expected life and the residual value of the relevant asset) to each other. If this is the case, it can be argued that this theory of depreciation connotes a self-defining set of physical relations and, as noted in Section 3, it also yields a set of mathematical functions parameterized by time. However, Heelan (1965) points that a system such as this is not a real system, for all its variables, even position are supposed to be defined with an infinite degree of precision, while data on a real system are only obtained up to a certain degree of precision. In accounting, systems such as the calculation of depreciation noted above are not real systems, rather they are used to determine accounting 
information. Musvoto (2011b) notes that the concept of error is completely ignored in accounting measurement. Hence, it can be argued that accounting information calculated using deterministic or causal theories cannot be taken seriously as it is determined using an ideal or abstract norm. Furthermore, Musvoto (2011c) argues that the process of determining depreciation is not based on properly defined deterministic or causal theories. He points out that there is no physical relation between time and cost that can give depreciation dimensions of cost per unit of time. This is because time is inferred through natural laws, while cost is inferred through psychological laws and to date there is no natural law that joins physical laws to psychological phenomena. Luce et al. (1990) also explain the need for physical relations in fundamental measurement, which forms the basis of deterministic or causal theories using weight measurement as follows:

In the weight case, we have three distinct ingredients ... First, there is an extensive theory of length measurement leading to ratio-scale representations. Second, there is an extensive theory of mass measurement leading to ratioscale representations. And third, there are two physical laws that relate the measures of length and weight via the mass involved. Newton's law connects the force called weight via the acceleration, due to gravity, to mass, so that in a fixed gravitational field weight is proportional to mass. And Hooke's law connects the force applied to a spring to its displacement, again as a direct proportion within certain limits of elastic deformation of the spring. Thus, the theory asserts (within certain limits) that weight and spring displacements are proportional. So the measurement procedure that uses a spring to measure weight directly is valid according to this theory. (325)

It is clear that in fundamental measurement, as in causal theories, all variables are described operationally through appropriate measuring processes, which map them onto the number field, i.e. there must be an explicit theory of the measurement of all the variables involved in the process of measurement. There should also be a theory of measurement that connects the entire separate measurable variable involved in the measurement of weight. Musvoto (2011b) notes that in finance the percentage rate of return of a portfolio with two securities $\mathbf{A}$ and $\mathbf{B}$ is given by the following expression: $\mathbf{R p}=\mathbf{W a} \times \mathbf{R a}+\mathbf{W b} \times \mathbf{R b}$, where $\mathbf{R p}$ is the percentage rate of return on a portfolio; Wa is the portfolio weight of security $\mathbf{A} ; \mathbf{R a}$ is the percentage return on portfolio $\mathbf{A} ; \mathbf{W b}$ is the portfolio weight of security $\mathbf{B}$; and $\mathbf{R b}$ is the percentage rate of return on security $\mathbf{B}$. He argues that although this theory forms the basis of all modern finance principles, there is no physical relation that connects all the variables together. Hence, it can be argued that current deterministic or causal theories in accounting and finance do not meet the requirements of causal or deterministic theories. For this reason, caution should be exercised when using information produced by such models.

\section{CONCLUSION}

Although causal theories are currently used in accounting and finance there is no basis to support their use, because they do not fit the requirements of deterministic or causal theories. Furthermore, according to the principles of representational measurement, causal theories are not readily applicable to social sciences due to the inadequate interpretation of the concatenation operation. In particular, the following has been established:

- $\quad$ Accounting and finance definitions are so vague and ambiguous that they are not suitable for use in causal theories.

- The use of causal theories requires that the variables involved in the models should comply with the principles of fundamental measurement. However, research has shown that accounting and finance variables cannot be measured using fundamental measurement principles.

- Accounting and finance information is produced using principles that do not hold in the real world. No concept of error is incorporated.

In view of the findings of this study, caution should be exercised when using information produced by the use of causal theories in accounting and finance. 


\section{AUTHOR INFORMATION}

Charmaine Scrimnger-Christian is a lecturer in Statistics at the School of Information Technology of the NorthWest University, Vaal Triangle Campus. She is also involved in statistical consultation for postgraduate students. Her research interests include Operational Research, Risk management, Conceptual knowledge systems, Multilevel Statistical Analysis and Statistics. E-mail: Charmaine.ScrimngerChristian@nwu.ac.za

S Wedzerai Musvoto is a senior lecturer in Financial Management and Accounting at the School of Accounting Sciences of the North-West University's Vaal Triangle Campus. He received his PhD from the University of Pretoria in 2008. Dr Musvoto is also affiliated with the Association of Chartered Certified Accountants and the Chartered Institute of Management Accountants. His research interests include accounting measurement, risk management and the implications of modern principles of measurement on finance theory development.

\section{REFERENCES}

1. Abdel-Magid, M. F. (1979). Toward a better understanding of the role of measurement in accounting. The Accounting Review, April, 346-357

2. Black, M. (1963). Reasoning with loose concepts. Dialogue, (2), 1-12

3. Bowerman, L., \& O'Connell, T. (1990). Linear statistical models. An applied approach. PWS-KENT Publishing Company

4. $\quad$ Chambers, R. J. (1997). Wanted: Foundations of accounting measurement. Abacus, 34(1), 36-47

5. $\quad$ Decoene, S., Onghena, P., \& Janssen, R. (1995). Representationalism under attack. Journal of Mathematical Psychology, 39, 234-242

6. Ellsberg, D. (1961). Risk ambiguity, and the savage axioms. Quarterly Journal of Economics, 75, 643-669.

7. Ellsberg, D. (1963). Risk ambiguity, and the savage axioms. Quarterly Journal of Economics, 77, 336-342

8. Fellner, W. (1978). Distortion of subjective probabilities as a reaction to uncertainty. Quarterly Journal of Economics, 75, 670-689

9. Flanders, D. P. (1961). Accountancy, systematized learning, and economics. The Accounting Review, 36(4), 564-576.

10. Haugens, R. A. (2001). Modern investment theory. $5^{\text {th }}$ edition. New York: Prentice Hall

11. Heelan, P. A. (1965). Quantum mechanics and objectivity. The Hague: N Nijioff

12. International Accounting Standards Board (IASB). 2009. International Financial Reporting Standards (IFRS) (2009). Including International Accounting Standards (IAS) and interpretations as at 1 January 2009: London: IASB.

13. Luce, R. D. (1997). Several unresolved conceptual problems of mathematical psychology. Journal of Mathematical Psychology, 41, 71-87

14. Luce, R. D., Krantz, D. H., Suppes, P., \& Tversk, A. (1971). Foundations of measurement. Volume 1. Additive and polynomial representations. New York: Academic Press

15. Luce, R. D., Krantz, D. H., Suppes, P., \& Tversk, A. (1990). Foundations of measurement. Volume 3. Representations, axiomatization, and invariance. New York: Academic Press.

16. Markowitz, H. M. (1952). Portfolio selection. Journal of Finance, 7(1), 77-91.

17. Mattesich, R. (1964). Accounting and analytical methods. Homewood III: Irwin

18. Mossin, J. (1966). Equilibrium in a capital market. Econometrica, 34(4)., 768-783

19. Musvoto, S. W. (2008). Applying the representational theory of measurement to accounting. (Doctoral thesis, University of Pretoria, 2008). Retrieved, 2010-12-11 from http://upetd.up.ac.za/thesis/available/etd03282009-125051/

20. Musvoto, S. W. (2011a). Implications of the crisis of objectivity in accounting measurement on the development of finance theory. International Business \& Economics Research Journal, 10(2),

21. Musvoto, S. W. (2011b). Implications of the homomorphism definition of measurement on accounting measurement theory. International Business \& Economics Research Journal - (10)5, 23-32

22. Musvoto S.W. (2011c) Rethinking depreciation as a process of measurement: An exposition of the incompatibility of the concept of depreciation with the representational measurement theory, International Business \& Economics Conference, New Orleans, Louisiana, USA, March 14-16, -ISSN 1539-8757 (print); 2157-9660 (online) 
23. Musvoto, W., \& Gouws, D. G. (2010). The concept of a scale in accounting measurement. South African Journal of Economic and Management Sciences, 13(4), 424-436

24. Narens, L. (2002). A meaningful justification for the representational theory of measurement. Journal of Mathematical Psychology, 46, 746-768

25. Ryan, B., Scapens, R. W., \& Theobald, M. (2002). Research method and methodology in finance and accounting. Second Edition. Mitcham, Surrey: Padstow, Cornwall

26. Sharpe, W. F. (1964). Capital asset prices: A theory of market equilibrium. Journal of Finance,19(3), 425442

27. Staubus, G. J. (1985). An induced theory of accounting measurement. The Accounting Review, 60(1), 5375.

28. Staubus, G. J. (2004). Two views of accounting measurement. Abacus, 40(3), 265-279.

29. Sterling, R. R. (1979). Towards a science of accounting. Accounting publications of Scholars book Co.

30. Stevens, S. S. (1951). Mathematics, measurement and psychophysics. In (Ed.). Handbook of Experimental psychology.pp.1-49, New York: Wiley

31. Vickrey, D. W. (1970). Is accounting a measurement discipline? Accounting Review, 45(4), 731-742

32. Walker, R. G., \& Jones, S. (2003). Measurement: A way forward, Abacus: 39(3), 356-374

33. Willet, R. J. (1992). Transactions theory, Stochastic processes and derived accounting measurement. ABACUS, 27(2), 117-134

34. Zebda, A. (1991). The problem of ambiguity and vagueness in accounting. Behavioural Research in Accounting, 3, 117-145 


\section{NOTES}

